\title{
BMJ Open Passive smoking at home is a risk factor for community-acquired pneumonia in older adults: a population-based case-control study
}

Jordi Almirall, ${ }^{1}$ Mateu Serra-Prat, ${ }^{2}$ Ignasi Bolíbar, ${ }^{3}$ Elisabet Palomera, ${ }^{2}$ Jordi Roig, ${ }^{4}$ Imma Hospital, ${ }^{5}$ Eugenia Carandell, ${ }^{6}$ Mercè Agustí, ${ }^{5}$ Pilar Ayuso, ${ }^{7}$ Andreu Estela, ${ }^{6}$ Antoni Torres, ${ }^{8}$ the Study Group of Community-Acquired Pneumonia in Catalan Countries (PACAP)

To cite: Almirall J, SerraPrat M, Bolíbar I, et al. Passive smoking at home is a risk factor for communityacquired pneumonia in older adults: a population-based case-control study. BMJ Open 2014;4:e005133. doi:10.1136/bmjopen-2014005133

- Prepublication history for this paper is available online. To view these files please visit the journal online (http://dx.doi.org/10.1136/ bmjopen-2014-005133).

Received 25 February 2014 Revised 15 May 2014 Accepted 22 May 2014

CrossMark

For numbered affiliations see end of article.

Correspondence to Dr Jordi Almirall; jalmirall@csdm.cat

\section{ABSTRACT}

Objective: To assess whether passive smoking exposure at home is a risk factor for communityacquired pneumonia (CAP) in adults.

Setting: A population-based case-control study was designed in a Mediterranean area with 860000 inhabitants $>14$ years of age.

Participants: 1003 participants who had never smoked were recruited.

Primary and secondary outcome measures: Risk factors for CAP, including home exposure to passive smoking, were registered. All new cases of CAP in a well-defined population were consecutively recruited during a 12-month period.

Methods: A population-based case-control study was designed to assess risk factors for CAP, including home exposure to passive smoking. All new cases of CAP in a well-defined population were consecutively recruited during a 12-month period. The subgroup of never smokers was selected for the present analysis.

Results: The study sample included 471 patients with CAP and 532 controls who had never smoked. The annual incidence of CAP was estimated to be 1.14 cases $\times 10^{-3}$ inhabitants in passive smokers and $0.90 \times 10^{-3}$ in non-passive smokers (risk ratio (RR) $1.26 ; 95 \% \mathrm{Cl} 1.02$ to 1.55 ) in the whole sample. In participants $\geq 65$ years of age, this incidence was $2.50 \times 10^{-3}$ in passive smokers and $1.69 \times 10^{-3}$ in nonpassive smokers (RR $1.48,95 \% \mathrm{Cl} 1.08$ to 2.03 ). In this last age group, the percentage of passive smokers in cases and controls was $26 \%$ and $18.1 \%$, respectively ( $p=0.039$ ), with a crude OR of $1.59(95 \%$ $\mathrm{Cl} 1.02$ to 2.38) and an adjusted (by age and sex) OR of $1.56(95 \% \mathrm{Cl} 1.00$ to 2.45$)$.

Conclusions: Passive smoking at home is a risk factor for CAP in older adults (65 years or more).

\section{INTRODUCTION}

Community-acquired pneumonia (CAP) is an important cause of morbidity and mortality in

\section{Strengths and limitations of this study}

- The effect of passive smoking at home on community-acquired pneumonia in adults is controversial.

- The present findings add new evidence of the unfavourable effect of exposure to passive smoking at home based on data from a large population-based study.

- It shows a significant effect only in participants aged 65 years or older.

- Passive smoking was assessed by a self-reported questionnaire which could lead to an imprecise exposure quantitative measure.

industrialised countries. In the general adult population, the annual incidence of CAP ranges between 1.6 and 13.4 cases/1000 inhabitants, with a need for inpatient care between $22 \%$ and $51 \%$, and a lethality of $3-24 \%,{ }^{1-3}$ which remained unchanged in recent years despite the use of preventive measures. ${ }^{4}$ There is strong evidence of an association between active tobacco smoking and the risk for $\mathrm{CAP}^{5-8}$ Tobacco has a direct and independent effect on the risk for CAP and may act indirectly causing chronic bronchitis or chronic obstructive pulmonary disease (COPD), which in turn are well-recognised risk factors for $\mathrm{CAP}^{8}$ Therefore, one of the main actions for preventing CAP is a smoking cessation intervention.

There has also been an increasing interest to assess the effects of passive smoking. Although some studies suggested that passive smoking may be associated with a higher risk of respiratory infections in children whose parents smoke ${ }^{9-11}$ and adults, ${ }^{12} 13$ the effect of exposure to passive smoking on CAP is still unclear. In most developed countries, exposure to tobacco smoke has been reduced by 
approximately $20-25 \%$ due to smoking bans, which prohibit tobacco smoking in workplaces and outdoor public areas. ${ }^{13}$ However, tobacco laws prohibiting smoking in workplaces and leisure spaces do not have any influence on tobacco consumption in the home environment. This study was aimed to assess the influence of passive smoking exposure at home on the occurrence of CAP in adults.

\section{PATIENTS AND METHODS}

A population-based case-control study designed to identify risk factors for CAP (Community-acquired pneumonia in Health Care Centres; PACAP study) was conducted in an extensive rural and urban area on the eastern coast of Spain, with predominantly Mediterranean climatic conditions. Details of the study have been previously published. ${ }^{14}$ An initial prospective phase allowed identification of all new cases of CAP diagnosed during a 1-year period and to estimate the incidence of CAP in the target population, which included 859033 inhabitants older than 14 years assigned to any of the 64 participating primary care centres. Control participants were frequency matched by age ( \pm 5 years), sex and primary healthcare area with cases. Controls were selected at random from the databases of the primary care centres. For the identification of cases, an active and exhaustive search of all cases of clinically suspected CAP presented over a 1-year period was conducted. To this purpose, an active surveillance system was established to ensure the identification of all cases of CAP diagnosed in public and private healthcare facilities in the study area. Predefined criteria for case registration were acute lower respiratory tract infection for which antibiotics had been prescribed, in association with the appearance of new or previously unknown focal signs on physical examination and radiography of the chest. All cases of CAP were periodically re-evaluated by chest radiography at monthly intervals until complete recovery. Patients with suspicion of CAP in whom another non-infectious respiratory disease was later confirmed were excluded from the study, as were patients with active tuberculosis, aspiration pneumonia and healthcare-associated pneumonia. Cases of CAP were followed up for 4 weeks or until complete recovery. A questionnaire on CAP risk factors was administered to cases and controls at home. When the participant could not directly answer the questions (cognitive impairment, disease or, for CAP cases, death), the questionnaire was administered to the closest family member or caregiver. The interviewers were physicians or nurses trained in interview techniques and in the administration of the study questionnaire. The instrument was structured into three sections related to the following aspects: (1) health habits and lifestyle; (2) chronic respiratory diseases and other clinical conditions; and (3) regular treatments during the past year. History of tobacco use, and passive smoking at work and at home were also recorded. Passive tobacco consumption was assessed by the question: 'Do you currently live with one or more smokers at home?' with two (yes/no) possible answers. All participants gave written informed consent.

\section{Data analysis}

For the purpose of this analysis, only cases and controls who never smoked were selected. Participants were further classified into passive smokers at home and non-passive smokers at home. The effect of passive smoking exposure at home on CAP was assessed by two strategies: (1) estimation of the annual incidence of CAP in passive and non-passive smokers and calculation of the relative risk (RR) and its 95\% CI using data from the prospective phase of the study; and (2) estimation of the OR and its 95\% CI by logistic regression analysis using data from the case-control study. To estimate the incidence of CAP in participants exposed and non-exposed to passive smoking, it was assumed that the proportion of passive and non-passive smokers at home in each age and sex group of the study population was the same as that observed in the control group sample, considered highly representative of the study population because of its random selection from primary care databases and with a $99.3 \%$ of population coverage. ${ }^{15}$ In the control group $(n=1326)$, overall prevalence of never smokers was $48.5 \%$ and the prevalence of passive smokers at home was $10.6 \%$ (or $26.3 \%$ of never smokers). These data were stratified by age and sex groups and applied to the general population distribution (Catalan Statistics Institute, http://www. idescat.cat) to determine the denominators (total population at risk) in the estimation of the CAP incidence. Moreover, the attributable risk (AR; exposed risk-nonexposed risk) and the aetiological fraction (AF) in exposed population (AF\%; (exposed risk-non-exposed risk) $\times 100$ / exposed risk) were estimated as impact measures of passive smoking. In the case-control study, OR was adjusted by age and sex since, in this analysis matching was broken when selecting only never smokers. Also, all analyses were made for the overall study population and stratifying by $<65$ and $\geq 65$ years of age. The Statistical Package for the Social Sciences (SPSS, V.15) was used for the analysis of data. Statistical significance was set at $\mathrm{p}<0.05$, or in the RR and OR estimations if the 95\% CI did not include 1.0.

\section{RESULTS}

A total of 1003 participants who never smoked were selected from the PACAP database study, 283 (28.2\%) of whom reported to be in contact with tobacco smoke at home and were classified as passive smokers at home. Among these cases, $75 \%$ were women (median age: 65 years, range 14-96), whereas $71 \%$ of controls were women (median age: 63 years, range 15-100). Standardised prevalence of passive smoking at home in the study population was estimated at $28.4 \%$. A comparison of the percentage of passive smokers between cases and controls did not show statistically significant differences either in the overall study sample $(30.4 \%$ vs $26.3 \%$, $\mathrm{p}=0.155$ ) or in the subset of participants younger than 65 years $(46.1 \%$ vs $33.8 \%, \mathrm{p}=0.931)$. However, in participants aged 65 years or older, the percentage of passive smokers was significantly higher in cases with CAP than in controls ( $26 \%$ vs $18.1 \%, \mathrm{p}=0.039$ ). Table 1 shows the effect 
Table 1 Effect of passive tobacco consumption at home on the risk of CAP

\begin{tabular}{|c|c|c|}
\hline Passive smoker & $\begin{array}{l}\text { Crude OR } \\
(95 \% \mathrm{Cl})\end{array}$ & $\begin{array}{l}\text { Adjusted OR } \\
(95 \% \mathrm{CI})^{\star}\end{array}$ \\
\hline $\begin{array}{l}\text { Overall study } \\
\text { population }\end{array}$ & $1.22(0.93$ to 1.61$)$ & $1.18(0.90$ to 1.57$)$ \\
\hline $\begin{array}{l}\text { Participants } \\
<65 \text { years }\end{array}$ & 1.02 (0.71 to 1.46$)$ & 0.98 (0.68 to 1.41$)$ \\
\hline $\begin{array}{l}\text { Participants } \\
\geq 65 \text { years }\end{array}$ & 1.59 (1.02 to 2.48$)$ & 1.56 (1.00 to 2.45$)$ \\
\hline
\end{tabular}

(OR) of passive smoking on CAP for the overall study sample and for the age subgroups, with a significant effect only in participants aged 65 years or more, with an OR that remained almost invariable after adjusting by age and sex. In the study sample, passive smoking exposure at home was not associated with other known risk factors for CAP, such as chronic bronchitis, COPD, upper respiratory tract infection in the previous month, hospital admission in the previous 5 years, history of any previously confirmed pneumonia, sudden changes of temperature in the workplace in the previous 3 months, so that passive tobacco consumption was not adjusted by these variables.

The annual incidence of CAP in participants exposed and non-exposed to passive smoking in the home environment, RR, AR and AF for the overall study sample and for subgroups of age is summarised in table 2. A statistically significant effect of passive tobacco exposure was observed in participants aged 65 years or older; in whom passive smoking carried a $48 \%$ increase in the risk for CAP.

\section{DISCUSSION}

The results of the present analysis show that age modifies the effect of passive smoking on CAP. Participants aged 65years or older passive smokers are at a higher risk for CAP than non-exposed participants with an OR of 1.59, while this effect disappeared in participants under
65 years of age. There is abundant scientific evidence of the effect of tobacco on CAP but evidence of the effect of passive smoking is scarcer. It is well known that smoking is one of the main independent risk factors for CAP and determines its severity ${ }^{716-18}$ This risk is directly associated with the number of cigarettes smoked and it reduces after quitting. ${ }^{8}$ Probably this may be explained by structural pulmonary lesions and alterations of the immune responseinnate and adaptative-as a result of smoking ${ }^{19} 20$ which may favour the presence and propagation of microorganisms in the bronchial tree. Also, tobacco consumption increases tissue oxidative stress especially in the lung provoking lesions in the respiratory epithelium, connective tissue and vascular endothelium, which may increase their sensitivity to the inflammatory aggression of the infection, ${ }^{19-21}$ even at low concentrations of smoke. ${ }^{22}$ Owing to these profound mechanisms, tobacco smoke may be an important risk factor for CAP also in passive smokers. ${ }^{9} 10$

The effect of passive smoking on the risk of CAP has been previously reported in patients older than 65 years requiring inpatient care for $\mathrm{CAP}^{12}$ and in patients between 18 and 64 years of age with pneumococcal bacteraemia. ${ }^{11}$ However, the influence of passive smoking exposure on the appearance of CAP in adults of all ages on the basis of a population-based study was not well known and uncertain. Nuorti et al $l^{11}$ showed that smoking was the main independent risk factor for invasive pneumococcal disease in immunocompetent adults aged between 18 and 64 years, with an OR of 4.1 in active smokers and 2.5 in passive smokers. In the present study, exposure to passive smoking in the home environment only showed an effect in participants 65 years or over, in whom a 59\% risk excess was observed. Age seems to modify the effect of passive smoking on CAP but it is not clear if this interaction is due to age 'per se' or if it is due to prolonged exposure or a different or more intense exposure pattern to passive tobacco smoke at home in elderly participants. Moreover, in older persons the defence mechanisms may be more impaired and outweighed by this aggression. By contrast, in

Table 2 Incidence of CAP and the impact of exposure to passive smoking at home

\begin{tabular}{|c|c|c|c|c|}
\hline Never smokers & $\begin{array}{l}\text { Annual incidence } \\
\text { of CAP }\end{array}$ & $\begin{array}{l}\text { Relative risk } \\
(95 \% \mathrm{Cl})\end{array}$ & $\begin{array}{l}\text { Attributable risk } \\
(95 \% \mathrm{Cl})\end{array}$ & $\begin{array}{l}\text { Aetiological } \\
\text { fraction, \% }\end{array}$ \\
\hline \multicolumn{5}{|c|}{ Overall study population } \\
\hline Passive smokers & $1.14 / 10^{3}$ inhabitants & \multirow[t]{2}{*}{1.26 (1.02 to 1.55$)$} & \multirow{2}{*}{$\begin{array}{l}0.235 / 10^{3} \text { inhabitants } \\
(0.234 \text { to } 0.235)\end{array}$} & \multirow[t]{2}{*}{20.6} \\
\hline $\begin{array}{l}\text { Non-passive } \\
\text { smokers }\end{array}$ & $0.90 / 10^{3}$ inhabitants & & & \\
\hline \multicolumn{5}{|c|}{ Participants aged $<65$ years } \\
\hline Passive smokers & $0.75 / 10^{3}$ inhabitants & \multirow[t]{2}{*}{1.14 (0.87 to 1.51$)$} & \multirow{2}{*}{$\begin{array}{l}0.094 / 10^{3} \text { inhabitants } \\
(0.094 \text { to } 0.095)\end{array}$} & \multirow[t]{2}{*}{12.5} \\
\hline $\begin{array}{l}\text { Non-passive } \\
\text { smokers }\end{array}$ & $0.66 / 10^{3}$ inhabitants & & & \\
\hline \multicolumn{5}{|c|}{ Participants aged $\geq 65$ years } \\
\hline Passive smokers & $2.50 / 10^{3}$ inhabitants & \multirow{2}{*}{1.48 (1.08 to 2.03$)$} & \multirow{2}{*}{$\begin{array}{l}0.811 / 10^{3} \text { inhabitants } \\
(0.810 \text { to } 0.812)\end{array}$} & \multirow[t]{2}{*}{32.5} \\
\hline $\begin{array}{l}\text { Non-passive } \\
\text { smokers }\end{array}$ & $1.69 / 10^{3}$ inhabitants & & & \\
\hline
\end{tabular}


younger participants, specific and non-specific defence mechanisms may counterbalance the aggression of tobacco smoke caused by other smokers.

The prevalence of passive smokers at home observed in the present study is very similar to that previously published regarding the Spanish population in 2005 (29.5\%), prior to the smoking ban coming into force, ${ }^{23}$ which reinforces the reliability of the present data. This prevalence indicates the magnitude of exposure to a factor which has a remarkable impact on the risk of CAP. Thus, approximately one-third of pneumonic episodes in passive smokers $>65$ years of age are due to exposure to tobacco smoke from other persons at home and could be avoided if this factor was eliminated. The present findings, together with evidence of the effectiveness of the pneumococcal vaccine, ${ }^{24}{ }^{25}$ in particular, the conjugate vaccine,${ }^{26}$ suggest that vaccination could be administered to active smokers and participants older than 65 years of age who cannot avoid being exposed to passive smoking in the household environment. The main study limitations include inaccuracy of quantitatively measured passive tobacco smoke exposure since exposure intensity was not considered and coinhabitats who smoke at home may go to smoke outside. However, this circumstance was the same for cases and controls and, although it may have diluted the expected effect, a bias was not introduced. We have not taken into account passive exposure at work or in public places, which is now forbidden but was allowed when the study was conducted, because our aim was focused on the effect of passive smoking at home.

In summary, the present study adds new evidence of the effect of passive smoking on CAP in adults from a population-based study. It shows a significant effect only in participants 65 years old or above, who may be exposed for a prolonged period of time, with a more intensive pattern of exposure and whose pulmonary defence mechanisms may be impaired or debilitated. These results must be taken into account when considering preventive measures for CAP in this specific age population, such as changes in lifestyle factors or vaccination.

\author{
Author affiliations \\ ${ }^{1}$ Critical Care Unit, Hospital de Mataró, Universitat Autònoma de Barcelona, \\ Ciber Enfermedades Respiratorias, CIBERES, Barcelona, Spain \\ ${ }^{2}$ Research Unit, Hospital de Mataró, CIBEREHD, Barcelona, Spain \\ ${ }^{3}$ Department of Clinical Epidemiology and Public Health, Institut de Recerca \\ Biomedica (IIB Sant Pau) Barcelona, Universitat Autònoma de Barcelona, \\ CIBERESP, Barcelona, Spain \\ ${ }^{4}$ Hospital Nostra Senyora de Meritxell, Escaldes-Engordany, Principat \\ d'Andorra \\ ${ }^{5}$ Institut Català de la Salut (ICS), Barcelona, Spain \\ ${ }^{6}$ IB-SALUT Balears, Palma de Mallorca, Spain \\ ${ }^{7}$ INSALUD, Valencia, Spain \\ ${ }^{8}$ Service of Pneumology, Institut Clínic del Torax, IDIBAPS, Hospital Clínic de \\ Barcelona. Universitat de Barcelona, CIBERES, Barcelona, Spain
}

Acknowledgements The authors thank Marta Pulido, MD, for editing the manuscript and editorial assistance. The fees for medical editing were paid by Fundació Privada Salut del Consorci Sanitari del Maresme.

Contributors JA, MSP, IB and AT have designed the study, contributed in the fieldwork and written the manuscript. EP has performed the statistical analysis. JR, IH, EC, MA, PA and AE contributed in the fieldwork. JA is the guarantor of the study.

Funding Fondo de Investigaciones Sanitarias (FIS 99/0002-01) and CIBER de Respiratorio 06/06/0028 Madrid, Spain.

\section{Competing interests None.}

Patient consent Obtained.

Ethics approval The study protocol was approved by the Ethics Committee of the Consorci Sanitari del Maresme (Barcelona, Spain).

Provenance and peer review Not commissioned; externally peer reviewed.

Data sharing statement No additional data are available.

Open Access This is an Open Access article distributed in accordance with the Creative Commons Attribution Non Commercial (CC BY-NC 3.0) license, which permits others to distribute, remix, adapt, build upon this work noncommercially, and license their derivative works on different terms, provided the original work is properly cited and the use is non-commercial. See: http:// creativecommons.org/licenses/by-nc/3.0/

\section{REFERENCES}

1. Torres A, Blasi F, Peetermans WE, et al. The aetiology and antibiotic management of community-acquired pneumonia in adults in Europe: a literature review. Eur J Clin Microbiol Infect Dis 2014;33:1065-79.

2. Torres A, Peetermans WE, Viegi G, et al. Risk factors for community-acquired pneumonia in adults in Europe: a literature review. Thorax 2013;68:1057-65.

3. Oseasohn R, Skipper BE, Tempest B. Pneumonia in a Navajo community: a two-year experience. Am Rev Respir Dis 1978;117:1003-9.

4. Gil-Prieto R, García-García L, Álvaro-Meca A, et al. The burden of hospitalisations for community-acquired pneumonia (CAP) and pneumococcal pneumonia in adults in Spain (2003-2007). Vaccine 2011;29:412-16.

5. Arcavi L, Benowitz NL. Cigarette smoking and infection. Arch Intern Med 2004;164:2206-16.

6. Hoffman LH, Strutton DR, Stang PE, et al. Impact of smoking on respiratory illness-related outpatient visits among 50 -to 75 -year-old in the United States. Clin Ther 2002;24:317-24.

7. Almirall J, Bolíbar I, Balanzó X, et al. Risk factors for community-acquired pneumonia in adults: a population-based case control study. Eur Respir J 1999:13:349-55.

8. Almirall J, González CA, Balanzó X, et al. Proportion of community-acquired pneumonia cases attributable to tobacco smoking. Chest 1999;116:375-9.

9. Vinogradova Y, Hippisley-Cox J, Coupland C. Identification of new risk factors for pneumonia: population-based case-control study. $\mathrm{Br} J$ Gen Pract 2009:59:e882-7.

10. Jones LL, Hashim A, McKeever T, et al. Parental and household smoking and the increased risk of bronchitis, bronchiolitis and other lower respiratory infections in infancy: systematic review and meta-analysis. Respir Res 2011;12:5.

11. Nuorti JP, Butler JC, Farley MM, et al. Active bacterial core surveillance team. Cigarette smoking and invasive pneumococcal disease. N Engl J Med 2000;342:681-9.

12. Loeb M, Neupane B, Walter SD, et al. Environmental risk factors for community-acquired pneumonia hospitalization in older adults. J Am Geriatr Soc 2009;57:1036-40.

13. Jiménez-Ruiz CA, Miranda JA, Hurt RD, et al. Study of the impact of laws regulating tobacco consumption on the prevalence of passive smoking in Spain. Eur J Public Health 2008;18:622-5.

14. Almirall J, Bolibar I, Serra-Prat M, et al.; Community-Acquired Pneumonia in Catalan Countries (PACAP) Study Group. New evidence of risk factors for community-acquired pneumonia: a population-based study. Eur Resp J 2008;31:1274-84.

15. http://www20.gencat.cat/docs/salut/Home/El\%20Departament/ Estadistiques\%20sanitaries/Enquestes/02 enquesta catalunya continua/Documents/Arxius/informeesca2012.pdf

16. Pastor P, Medley F, Murphy TV. Invasive pneumococcal disease in Dallas County, Texas: results from population-based surveillance in 1995. Clin Infect Dis 1998;26:590-5.

17. Garcia-Vidal C, Ardanuy C, Tubau F, et al. Pneumococcal pneumonia presenting with septic shock: host- and pathogen-related factors and outcomes. Thorax 2010;65:77-81. 
18. Marrie TJ, Shariatzadeh MR. Community-acquired pneumonia requiring admission to an intensive care unit: a descriptive study. Medicine (Baltimore) 2007;86:103-11.

19. Hodge S, Hodge GI, Ahern J, et al. Smoking alters alveolar macrophage recognition and phagocytic ability. Am J Respir Cell Mol Biol 2007;37:748-55.

20. Huttunen R, Heikkinen T, Syrjänen J. Smoking and the outcome of infection. J Intern Med 2011;269:258-69.

21. Arnson $\mathrm{Y}$, Shoenfeld $\mathrm{Y}$, Amital $\mathrm{H}$. Effects of tobacco smoke on immunity, inflammation and autoimmunity. J Autoimmun 2010;34: J258-65.

22. Strulovici-Barel Y, Omberg L, O'Mahony M, et al. Threshold of biologic responses of the small airway epithelium to low levels of tobacco smoke. Am J Respir Crit Care Med 2010;182:1524-32.
23. Jiménez-Ruiz CA, Miranda JAR, Hurt RD, et al. Study of the impact of laws regulating tobacco consumption on the prevalence of passive smoking in Spain. Eur J Public Health 2008;18:622-5.

24. Pearson WS, Dube SR, Ford ES, et al. Influenza and pneumococcal vaccination rates among smokers: data from the 2006. Behavioral Risk Factor Surveillance System. Prev Med 2009;48:180-3.

25. Centers for Disease Control and Prevention. Recommended adult immunization schedule. United States. 2011 Proposed Revisions. Advisory Committee on Immunization Practices. October 28, 2010.

26. De Roux A, Schmöele-Thoma TR, Siber GR, et al. Comparison of pneumococcal conjugate polysaccharide and free polysaccharide vaccines in elderly adults: conjugate vaccine elicits improved antibacterial immune responses and immunological memory. Clin Infect Dis 2008;46:1015-23. 